\title{
1 Global patterns of body size evolution are driven by precipitation in
}

2 legless amphibians

3

4 Daniel Pincheira-Donoso ${ }^{1,6}$, Shai Meiri², Manuel Jara ${ }^{3}$, Miguel Ángel Olalla-Tárraga ${ }^{4}$ \& Dave J.

5 Hodgson $^{5}$

6

7

8

${ }^{1}$ MacroBiodiversity Lab, School of Science and Technology, Department of Biosciences, Nottingham Trent University, Nottingham, NG11 8NS, United Kingdom (ORCID ID: 0000-0002-0050-6410)

2Steinhardt Museum of Natural History \& School of Zoology, Tel Aviv University, Tel Aviv, 6997801, Israel ${ }^{3}$ School of Life Sciences, Joseph Banks Laboratories, University of Lincoln, Brayford Campus, Lincoln, LN6 7DL, United Kingdom

${ }^{4}$ Departamento de Biología, Geología, Física y Química Inorgánica, Universidad Rey Juan Carlos, Tulipán s/n, Móstoles, 28933, Madrid, Spain

${ }^{5}$ Centre for Ecology and Conservation, College of Life and Environmental Sciences, University of Exeter, Cornwall Campus, Penryn, TR10 9FE, Cornwall, United Kingdom

${ }^{6}$ Corresponding author: daniel.pincheiradonoso@ntu.ac.uk

Running head: Macroecology of body size in caecilians 19 (1) 1 2 3 4 5 6 7 8 9 0 1 


\section{Abstract}

Body size shapes ecological interactions across and within species, ultimately influencing the evolution of large-scale biodiversity patterns. Therefore, macroecological studies of body size provide a link between spatial variation in selection regimes and the evolution of animal assemblages through space. Multiple hypotheses have been formulated to explain the evolution of spatial gradients of animal body size, predominantly driven by thermal (Bergmann's rule), humidity ('water conservation hypothesis'), and resource constraints ('resource rule', 'seasonality rule') on physiological homeostasis. However, while integrative tests of all four hypotheses combined are needed, the focus of such empirical efforts needs to move beyond the traditional endotherm-ectotherm dichotomy, to instead interrogate the role that variation in lifestyles within major lineages (e.g., Classes) play in creating neglected scenarios of selection via analyses of largely overlooked environment-body size interactions. Here, we test all four rules above using a global database spanning $99 \%$ of modern species of an entire Order of legless, predominantly underground-dwelling amphibians (Gymnophiona, or caecilians). We found a consistent effect of increasing precipitation (and resource abundance) on body size reductions (supporting the water conservation hypothesis), while Bergmann's, the seasonality and resource rules are rejected. We argue that subterranean lifestyles minimize the effects of aboveground selection agents, making humidity a dominant selection pressure - aridity promotes larger body sizes that reduce risk of evaporative dehydration, while smaller sizes occur in wetter environments where dehydration constraints are relaxed. We discuss the links between these principles with the physiological constraints that may have influenced the tropically-restricted global radiation of caecilians.

Keywords: Bergmann's rule, resource rule, seasonality rule, water conservation hypothesis, body size, caecilians, Gymnophiona 


\section{Introduction}

The evolution of predictable geographic patterns of trait distribution across animal species is one of the most intriguing features of biodiversity (Gaston \& Blackburn, 2000). Variation in fecundity, longevity, metabolic rates, and diversification are shaped by spatial gradients in natural selection (Brown et al., 2004; Scharf et al., 2015; Pincheira-Donoso \& Hunt, 2017; Schluter \& Pennell, 2017). Importantly, the dependence of these traits on environmental factors is intrinsically influenced by body size, which varies through space (Peters, 1983; Smith \& Lyons, 2013). Therefore, understanding the role of environment-body size relationships in the evolution of biodiversity patterns is a primary ambition in macroecology (Gaston et al., 2008). For nearly two centuries, a range of 'ecogeographic rules' have aimed to elucidate the drivers behind geographic patterns of body size evolution. The leading rule, Bergmann's rule - increases in body sizes toward colder climates as greater body mass, relative to surface area, reduces heat loss (Bergmann, 1847) - has set the theoretical benchmark for research on large-scale patterns of animal size (James, 1970; Blackburn et al., 1999; Meiri \& Dayan, 2003). However, evidence from across the animal kingdom reveals that Bergmann's rule tends to hold in endotherms (Freckleton et al., 2003; Meiri \& Dayan, 2003; de Queiroz \& Ashton, 2004; Olson et al., 2009; but see Riemer et al., 2018), while its validity is inconsistent in ectotherms (Ashton \& Feldman, 2003; Olalla-Tarraga et al., 2006; Olalla-Tarraga \& Rodriguez, 2007; Pincheira-Donoso et al., 2007, 2008; Adams \& Church, 2008; Pincheira-Donoso \& Meiri, 2013; Feldman \& Meiri, 2014; Moreno-Azocar et al., 2015; Amado et al., 2019; Slavenko et al., 2019). These discrepancies have discredited temperature as a primary driver of body size clines (Pincheira-Donoso, 2010; Meiri, 2011; Olalla-Tarraga, 2011). Essentially, while larger body size optimises preservation of endothermic metabolic heat, the dependence of ectotherms on external sources of heat requires them to gain body heat in the first place (Ashton \& Feldman, 2003; OlallaTarraga et al., 2006; Pincheira-Donoso et al., 2008).

As a result, macroecological theories of animal size have explored alternative sources of selection as drivers of body size evolution. The roles that resource abundance and humidity play in metabolic and physiological homeostasis as functions of body size (Rosenzweig, 1968; Yom-Tov \& Nix, 1986; Brown \& Sibly, 2006; McNab, 2010), have led to the formulation of a range of competing hypotheses: (I) the 'resource rule', suggests that increasing resource abundance (primary productivity) relaxes the constraints on upper limits of body size, permitting the evolution of larger species (Rosenzweig, 1968; Geist, 1987; Yom-Tov \& Geffen, 2006; McNab, 2010), while not selecting against small body sizes. The mechanisms are potentially multiple. For example, more productive areas may facilitate energy investment into body growth without a trade-off with reproduction (Roff, 2002; McNab, 2010). Also, in poorly productive regions (e.g., deserts), fitness can benefit from reductions in resource requirements via smaller body size (McNab, 2010); (ii) The 
'water conservation hypothesis' (WCH), predicts stronger selection for larger size towards arid environments, given that rates of desiccation decrease with increasing body mass (Nevo, 1973; Olalla-Tarraga et al., 2009; Gouveia \& Correia, 2016). This may be especially prevalent in organisms prone to dehydration, such as amphibians. Importantly, the WCH's predictions conflict with the resource rule. First, the WCH predicts larger size in arid regions, while the resource rule predicts larger size in productive (usually wet) areas. Also, such predictions are sensitive to thermoregulation (ectothermy vs endothermy), body structures (e.g., skin permeability), and lifestyle (e.g., habitat) among lineages, because factors such as energetic requirements and osmoregulation are expected to influence the adaptive trajectories of body size. For example, while heat production implies high metabolic expenditure of energy for endotherms, the dependence of ectotherms on environmental heat neutralises such pressures (Brown et al., 2004; Angilletta, 2009); finally (iii) the 'seasonality (or 'fasting-endurance') rule', predicts that increasing seasonality selects for increased body size to enhance tolerance to unstable environments (Lindsey, 1966; Boyce, 1979; Calder, 1984). Given the contrasting mechanisms that these hypotheses offer to explain the same phenomenon, evidence supporting them has been conflicting across lineages (Meiri et al., 2005; Yom-Tov \& Geffen, 2006; Olalla-Tarraga \& Rodriguez, 2007; Olalla-Tarraga et al., 2009; Oufiero et al., 2011; Pincheira-Donoso \& Meiri, 2013; Gouveia \& Correia, 2016; Kelly et al., 2018; Amado et al., 2019). Furthermore, our understanding of body size macroecology has fundamentally been advanced based on above-ground organisms, while analyses on fossorial lineages remain anecdotal (e.g., Meiri \& Dayan, 2003; Measey \& Van Dongen, 2006; Feldman \& Meiri, 2014).

We employ the most comprehensive global dataset of caecilian amphibians (Order Gymnophiona) to date, to test the core predictions of the above four rules. Caecilians are tropically widespread amphibians that combine peculiar features expected to alter the way selection from environmental factors operates on homeostasis relative to most tetrapods (Vitt \& Caldwell, 2014). They have elongated, legless bodies that predominantly occupy underground microhabitats ("fossoriality"; Pough et al., 2015) that offer relatively stable thermal environments isolated from multiple pressures that operate above-ground (Buffenstein \& Jarvis, 2002; Wells, 2007; Healy et al., 2014). Their skins are also highly permeable, which intensifies selection from climatic factors (Steele \& Louw, 1988; Wells, 2007). Our study thus provides the most comprehensive analysis of the classic and emerging hypotheses underlying body size evolution rules.

\section{Material and Methods}

\section{Species data}


118 We gathered an exhaustive global-scale dataset on caecilians spanning body size data for $>99 \%$ (207 out of

119 208; Suppl. Table 1) of the world's known species. We followed the taxonomy in Frost (2018). To investigate 120 the above set of hypotheses, we used the largest recorded total body length (from snout to tail tip) as the 121 proxy for body size, as this is the most commonly reported measure of size for caecilians (Wells, 2007; 122 Pough et al., 2015). Data were collected from the primary literature (which includes all species described 123 recently) and from monographic books (Suppl. Material 2). In addition, we created an environmental dataset 124 (see below), extracted from distribution maps, for $93 \%$ of the species -40 of which were originally created as part of this study (Fig. 1; Suppl. Table 1). This dataset is part of XXX (details blinded following requirements from the Editorial Office - to be disclosed upon acceptance).

\section{Environmental predictors}

To investigate the role of environmental factors as drivers of geographic variation in body size across caecilians, we created a dataset covering a range of candidate predictors representing geographic location, climate and primary productivity. To extract these data, we first obtained maps of extant known geographic distribution for all species available at the IUCN archive (www.iucnredlist.org). We created maps for 40 species for which this information was unavailable, by collecting the geographic position system (GPS) coordinates provided in the papers in which they were described. In some cases, these records are only available for the specimens officially assigned to the type series, while additional existing records are only shown in maps. In those cases, we obtained the exact GPS position of each additional point in the published maps using Google Earth Pro. This protocol resulted in a dataset covering 191 caecilian species (92\% of their global diversity). The remaining species were not mapped because their distributions remain unknown, unclear or inadequately described. To create a species-level dataset of environmental and geographic predictors, we assigned to each species a single value per predictor, calculated as the average of all values obtained by dividing the geographic range polygon of each variable for each species into 2.5 arc-minute grid cells ( 5x5 kilometres) using ArcGIS 10.0.

Firstly, we used latitude (in degrees from the Equator) given its classical status as geographic predictor. Latitude data were extracted as the midpoint from each individual species map. Second, a set of climatic predictors were obtained from the WorldClim 2 (www.worldclim.org) archive (Hijmans et al., 2005; Fick \& Hijmans, 2017), and are expressed at a spatial resolution of 2.5 arc-minutes ( $5 \mathrm{~km}$ at the equator). These data are the result of collections of monthly measurements of multiple bioclimatic variables conducted between $1950-2000$ by a large number of scattered weather stations around the world, and interpolated for areas of poorer coverage (Hijmans et al., 2005). The climatic variables consist of mean annual temperature 
150 (averaged across the 12 months of the year, in degrees Celsius), temperature seasonality (calculated as the

151 SD of the annual mean temperature $\times 100$, in degrees Celsius), mean annual precipitation (the amount of

152 rainfall measured in millimetres a year), and precipitation seasonality (coefficient of variation of monthly

153 precipitation across the year). Finally, we used net primary productivity (NPP, the net amount of solar energy

154 converted to plant organic matter through photosynthesis - measured in units of elemental carbon per year,

155 on a spatial resolution of $0.25^{\circ}, \mathrm{gC} / \mathrm{m}^{2} / \mathrm{yr}$, log transformed) as a proxy for resource availability (Imhoff et al.,

156 2004). These data were then assigned to each caecilian species in our dataset, and all extractions of

157 variables and their visualization on climatic maps (Figure 1; Supplementary Material 3) were performed using

158 ArcGIS software version 10.0 (www.esri.com).

159

Quantitative analyses and phylogenetic control

161 We performed phylogenetic regressions to investigate the role of environmental factors in shaping spatial

162 gradients of caecilian body size. We first tested for latitudinal gradients in body size by regressing logtransformed total body length against (absolute) latitude. Although latitude is a classic 'catch-all' predictor in macroecology, it represents a proxy for a set of environmental conditions that vary through space. Therefore, we further performed phylogenetic univariate and multiple regressions of log(body size) per species against environmental temperature (mean and seasonal range), annual precipitation (mean and seasonal range), and NPP. This series of regression analyses were subsequently repeated for the American (predominantly South American) assemblage of caecilians, as it concentrates $48 \%$ of the world's species (the rest being spread throughout the global tropics; Fig. 1). Similarly, the analyses were further repeated for all caecilians excluding the family Typhlonectidae (a clade of large, aquatic species; Wells, 2007; Pough et al., 2015), to directly address our core questions on fossorial species only, and then for the Typhlonectidae only. In all analyses, predictors were log-transformed and then scaled to have zero mean and unit variance. While logtransformation provided the best model checks of homogeneity of variance and normality of residuals, scaling prevented any instability of regression models caused by the inclusion of explanatory variables measured on different scales and with values far from the intercept. We performed the univariate regressions to demonstrate what conclusions might be drawn from naïve analyses of single environmental factors, and to confirm the robustness of the multiple regression results. We then considered the significance of the explanatory variables in a full multiple regression of their main effects (i.e. excluding interactions among explanatory variables), as a direct comparison of the relevance of temperature (classical heat-conservation mechanism for Bergmann's rule), the NPP (as a proxy for the resource rule) and the effects of rainfall on body size (as predicted by the WCH and the seasonality rule). For all analyses we used Akaike's Information 
182

183

184

185

186

187

188

189

190

Criterion (AIC) to compete the information content of rival models. For univariate regressions, each explanatory variable was considered important if its regression lay $>2$ AIC units below the null model.

To further assess the multiple regressions, we performed multi-model inference analyses. We used AIC and Akaike model weights to reduce the whole set of models employing a dredging approach that retains a confidence subset of models that lay within 6 AIC units of the most informative model. This method removes models that have spurious parameter estimates due to poor model fit above the chosen AIC threshold (Richards, 2005; Harrison et al., 2018). The importance of each explanatory variable was judged according to AIC-weighted mean effect sizes averaged across the subset of regression models, and are presented as AIC-weighted slope estimates $+/-95 \%$ confidence intervals to estimate the significance of the effect of each predictor on body size (Table 1). This procedure is robust given that information is contained in well-fitting but non-optimal models for parameter estimates (with confidence intervals), which would, in contrast, be lost with a single best-fit model (i.e., a step-wise approach) (Burnham et al., 2011). These analyses were performed using the package 'MuMIn' (Barton, 2017) implemented in R (R Development Core Team, 2017).

All regression models included phylogenetic control. We employed Jetz \& Pyron's (2018) phylogeny, from which we extracted all 183 caecilians species ( $88 \%$ of the Order's diversity) for which geographic, and hence environmental, data are available (Supplementary Table 1). We tested the significance of the value of Pagel's lambda, which measures the influence of shared evolutionary history on the divergence of regression residuals among species (Pagel, 1999). Phylogenetic regressions were performed using the 'ape' (Paradis et al., 2004) and 'nlme' (Pinheiro et al., 2018) packages in R.

\section{Results}

Body size varies considerably across caecilians, ranging from $112 \mathrm{~mm}$ in the smallest species (Grandisonia brevis and Microcaecilia iwokramae), to over 1,600mm in the largest (Caecilia guntheri; Figs. 1, 2; Supplementary Table S1). The frequency distribution of raw body size across species is significantly rightskewed (Shapiro-Wilk's test, $W=0.77, d f=206, P<0.001$; Fig. 2), which remains significantly right-skewed in the log-transformed data $(W=0.97, d f=206, P<0.001 ;$ Fig. 2).

\section{Latitudinal gradients of body size}

Our analyses failed to identify a signal for latitude in shaping the distribution of caecilian body sizes either globally or in the new world (Table 1; Fig. 3). The same analyses repeated for America, and for fossorial and 
aquatic caecilians separately, showed qualitatively identical results (Table 1). All findings remained consistent with and without phylogenetic control.

\section{Environmental predictors of body size}

Our phylogenetic regression analyses incorporating environmental variables revealed consistently high degrees of phylogenetic signal in model residuals, with Pagel's lambda of 0.57 for the multiple regression with all predictors $(\triangle \mathrm{AIC}=96.2$ comparing model with optimised lambda to a model with lambda fixed to zero). Regarding tests of the four core rules, our analyses based on the global dataset revealed that body sizes across species decrease with increasing annual precipitation, supporting the WCH (Table 1; Fig. 3). Likewise, analyses performed for fossorial and aquatic families separately revealed significant increases in body size at drier regions among underground-dweller species, in both the multiple and the univariate models (while the analyses restricted to aquatic caecilians failed to identify any significant predictors of body size variation). In contrast, measures of temperature, productivity and seasonality (either in temperature or in rainfall) showed no effect on body size variation (Table 1; Fig. 3), rejecting the three competing hypotheses. The univariate global model showed a nearly significant role for NPP as a driver of body size variation, but the relationship is negative, in opposition to the resource rule (Table 1; Fig. 3). These findings remained consistent across multi- and univariate regression analyses, which retained decreases in annual precipitation as the only significant predictor of larger body sizes through space (Table 1; Fig. 3). The models restricted to American caecilians failed to show effects for any of the predictors (the univariate model revealed a marginally non-significant effect of NPP on body size gradients. However, consistent with the global univariate model, the relationship is negative, thus conflicting with the core prediction of the resource rule). None of the models identified either measures of temperature as predictors of body size variation, rejecting Bergmann's rule and the heat-conservation mechanism (Table 1).

\section{Discussion}

Our study provides global-scale evidence supporting the $\mathrm{WCH}$ in an entire Order of predominantly fossorial tetrapods, while it reinforces the limited generality of Bergmann's rule and its alternatives (Blackburn et al., 1999; Olalla-Tarraga et al., 2009; Pincheira-Donoso, 2010), especially among ectotherms. In contrast with predictions from classic macroecological rules (Bergmann, 1847; James, 1970; Blackburn et al., 1999; McNab, 2010), our analyses failed to identify a role for temperature, resource abundance, seasonality or latitude as drivers of caecilian body size gradients. Instead, we show that decreases in precipitation 
244 significantly constrain the minimum 'viable' body size for fossorial (but not for aquatic) species, favouring 245 larger sizes as aridity increases. Thus, in contrast with the positive relationship between precipitation (as a 246 prevailing driver of resource abundance) and body size predicted by the resource rule (Yom-Tov \& Geffen, 247 2006; McNab, 2010), the relationship we observed is the opposite, with wetter environments correlating 248 positively with NPP but favouring smaller body sizes (and the only analysis that identified NPP as a 249 marginally non-significant predictor is negatively correlated with body size, opposing the resource rule; Table 250 1). Macroecological studies on amphibians have revealed highly conflicting evidence for a role of 251 temperature as an agent of spatial gradients in body size (Feder et al., 1982; Ashton, 2002; Olalla-Tarraga \& 252 Rodriguez, 2007; Adams \& Church, 2008; Cvetkovic et al., 2009), and the only known study on caecilians, 253 on one species, showed a link with elevation (Measey \& Van Dongen, 2006). In contrast, the role of water254 deprivation as a source of selection for larger body size as an adaptation to reduce rates of evapotranspiration has increasingly gained support (Olalla-Tarraga et al., 2009; Gouveia \& Correia, 2016; Amado et al., 2019). Our evidence, stemming from a complete coverage of caecilians, strongly supports the hypothesis that increases in body size are promoted by aridity - in particular among non-aquatic species, which reinforces the functional role of water conservation. Consequently, we suggest an explanation that relies on the hydroregulatory advantages of larger body size in water-deprived environments, and the life history advantages emerging in environments in which selection from humidity is relaxed.

\section{Natural selection from precipitation and the macroecology of body size}

Although our results identified precipitation as the only significant driver of geographic gradients of body size in caecilians, the observed negative relationship between precipitation (or NPP) and body size is incompatible with the prediction of the resource rule. Essentially, although selection from resource availability affects body size across animals in general (in different directions depending on whether abundance is low or high), such effects are expected to differ between endotherms and ectotherms given their differences in metabolic demands (Angilletta, 2009). Indeed, the production of constant, high body heat in endotherms is 'exceedingly' costly (Angilletta, 2009), being thus implicated in the evolution of most life history adaptations (Stearns, 1992; Brown \& Sibly, 2006; Angilletta, 2009). In contrast, such resource-intensive thermoregulation is not an issue in ectotherms (Meiri et al., 2013). Hence, we suggest that the global macroecology of caecilian body sizes is caused by a relaxation of selection from water-deprivation on body size as species occupy wetter environments, consistent with the $\mathrm{WCH}$. Towards the dry extreme of the wetness spectrum, the evolution of larger body size reduces relative rates of water loss. We suggest that for fossorial amphibians, such as most caecilians, the levels of soil moisture are a primary source of selection on body 
size mediated by the need to maintain stable levels of body water. Caecilians have especially high rates of evaporative water loss through the body surface (Wells, 2007) compared to other vertebrates, including amphibians, which is thought to constrain them to their fossorial lifestyles (Steele \& Louw, 1988; Wells, 2007). Even the 'dermal scales' that cover the skin of caecilians do not seem to reduce rates of water loss (Wells, 2007), having instead a role in underground locomotion (Duellman \& Trueb, 1994; Wells, 2007). Therefore, as wetness declines, the lower bound of body size is progressively constrained towards larger body mass for hydric homeostasis, leading to the prediction that towards drier environments the minimum level of body size across species increases. The same principle could potentially affect selection on offspring size.

On the other hand, towards the wet end of the spectrum, where hydroregulatory constraints that force caecilians to remain above a 'minimum viable' body size are gradually relaxed as humidity increases, selection is predicted to maximise life history pace via body size reductions. In line with this view, massspecific rates of life history productivity (e.g., faster production of offspring biomass) and metabolism have been shown to consistently increase as body size decreases (Peters, 1983; Brown \& Sibly, 2006; Sibly \& Brown, 2007; Meiri et al., 2012). Given that fitness can be defined as birth rates minus death rates (Brown \& Sibly, 2006), this scaling principle is expected to express particularly when lifestyle minimises mortality rates (e.g., via reduced predation). Fossorial lifestyles, in particular, buffer the intensity of selection from climatic and ecological pressures (Buffenstein \& Jarvis, 2002; Sibly \& Brown, 2007; Healy et al., 2014). Therefore, the fitness gains resulting from increases of productivity are expected to drive adaptive evolution of smaller body sizes in caecilians as hydroregulatory constraints are relaxed towards wetter environments.

\section{Body plan and the global radiation of caecilians}

The hypothesis that body size adjusts along humidity gradients to maximise hydric homeostasis might shed light on the conditions that have underlain the global radiation of these amphibians. Traditionally, the body mass to surface area ratio has been employed to explain decreasing heat loss rates as body size increases, being therefore favoured towards colder climates (i.e., Bergmann's rule; James, 1970; Blackburn et al., 1999). However, the thermodynamic efficiency of this relationship strongly depends on the body plan of a lineage. For example, in vertebrates with 'regular', legged body plans, the efficiency of increases of body mass in reducing heat loss are straightforward. In contrast, in lineages characterized by disproportionately elongated and narrow body plans (such as caecilians, but also snakes and amphisbaenians), the mass-tosurface hypothesis loses strength as increasing body elongation results in proportional increases in surface area. Therefore, we suggest that an elongated body plan intrinsically facilitates water loss, and hence, the 
'naked' amphibian skin of caecilians is expected to only be viable in humid environments. Thus, according to this hypothesis, the radiation of caecilians across increasingly drier environments would demand body mass increases proportional to aridity, which is likely to have been historically prevented by the physical restrictions of their underground lifestyles. Consequently, this is a potential explanation why caecilians are confined to wet environments, compared to the higher levels of environmental tolerance of anurans and salamanders.

\section{References}

Adams, D.C. \& Church, J.O. (2008) Amphibians do not follow Bergmann's rule. Evolution, 62, 413-420.

Amado, T.F., Bidau, C.J. \& Olalla-Tárraga, M.A. (2019) Geographic variation of body size in New World anurans: energy and water in a balance. Ecography, 42, 456-466.

Angilletta, M.J. (2009) Thermal adaptation. A theoretical and empirical synthesis, Oxford University Press, Oxford.

Ashton, K.G. (2002) Do amphibians follow Bergmann's rule? Canadian Journal of Zoology, 80, 708-716.

Ashton, K.G. \& Feldman, C.R. (2003) Bergmann's rule in nonavian reptiles: turtles follow it, lizards and snakes reverse it. Evolution, 57, 1151-1163.

Barton, K. (2017) MuMIn: Multi-model inference. R package version 1.40.0, R Foundation for Statistical Computing, Vienna.

Bergmann, C. (1847) Ueber die Verhaltnisse der warmeokonomie der thiere zu ihrer grosse. Gottinger Studien, 3, 595-708.

Blackburn, T.M., Gaston, K.J. \& Loder, N. (1999) Geographic gradients in body size: a clarification of Bergmann's rule. Diversity and Distributions, 5, 165-174.

Boyce, M.S. (1979) Seasonality and patterns of natural selection for life histories. American Naturalist, 114, $569-583$.

Brown, J.H., Gillooly, J.F., Allen, A.P., Savage, V.M. \& West, G.B. (2004) Toward a metabolic theory of ecology. Ecology, 85, 1771-1789.

Brown, J.H. \& Sibly, R.M. (2006) Life-history evolution under a production constraint. Proceedings of the National Academy of Sciences, USA, 103, 17595-17599.

Buffenstein, R. \& Jarvis, J.U.M. (2002) The naked mole rat: a new record for the oldest living rodent. Science of Aging Knowledge Environment, 21, pe7.

Burnham, K.P., Anderson, D.R. \& Huyvaert, K.P. (2011) AIC model selection and multimodel inference in behavioral ecology: some background, observations, and comparisons. Behavioral Ecology and 
Sociobiology, 65, 23-35.

Calder, W.A. (1984) Size, function and life history, Harvard University Press, Massachusetts.

Cvetkovic, D., Tomasevic, N., Ficetola, G.F., Crnobrnja-Isailovic, J. \& Miaud, C. (2009) Bergmann's rule in amphibians: combining demographic and ecological parameters to explain body size variation among populations in the common toad Bufo bufo. Journal of Zoological Systematics and Evolutionary Research, 47, 171-180.

Duellman, W.E. \& Trueb, L. (1994) Biology of Amphibians, Johns Hopkins University Press, Maryland.

Feder, M.E., Papenfuss, T.J. \& Wake, D.B. (1982) Body size and elevation in neotropical salamanders. Copeia, 1982, 186-188.

Feldman, A. \& Meiri, S. (2014) Australian snakes do not follow Bergmann's rule. Evolutionary Biology, 41, 327-335.

Fick, S.E. \& Hijmans, R.J. (2017) Worldclim 2: New 1-km spatial resolution climate surfaces for global land areas. International Journal of Climatology, 37, 4302-4315.

Freckleton, R.P., Harvey, P.H. \& Pagel, M. (2003) Bergmann's rule and body size in mammals. American Naturalist, 161, 821-825.

Frost, D.R. (2018) Amphibian Species of the World: an Online Reference. Version 6.0 (January 2018). American Museum of Natural History, New York, USA, Electronic.

Gaston, K.J. \& Blackburn, T.M. (2000) Pattern and process in macroecology, Blackwell Science, Massachusetts.

Gaston, K.J., Chown, S.L. \& Evans, K.L. (2008) Ecogeographical rules: elements of a synthesis. Journal of Biogeography, 35, 483-500.

Geist, V. (1987) Bergmann's rule is invalid. Canadian Journal of Zoology, 65, 1035-1038.

Gouveia, S.F. \& Correia, I. (2016) Geographical clines of body size in terrestrial amphibians: water conservation hypothesis revisited. Journal of Biogeography, 43, 2075-2084.

Harrison, X.A., Donaldson, L., Correa-Cano, M.E., Evans, J., Fisher, D.N., Goodwin, C.E.D., Robinson, B.S., Hodgson, D.J. \& Inger, R. (2018) A brief introduction to mixed effects modelling and multi-model inference in ecology. PeerJ, 6, e4794.

Healy, K., Guillerme, T., Finlay, S., Kane, A., Kelly, S.B.A., McClean, D., Kelly, D.J., Donohue, I., Jackson, A.L. \& Cooper, N. (2014) Ecology and mode-of-life explain lifespan variation in birds and mammals. Proceedings of the Royal Society of London B, Biological Sciences, 281, 20140298.

Hijmans, R.J., Cameron, S.E., Parra, J.L., Jones, P.G. \& Jarvis, A. (2005) Very high resolution interpolated climate surfaces for global land areas. International Journal of Climatology, 25, 1965-1978. 
372 Imhoff, M.L., Bounoua, L., Ricketts, T., Loucks, C., Harriss, R. \& Lawrence, W.T. (2004) Global patterns in 373 human consumption of net primary production. Nature, 429, 870-873.

374 James, F.C. (1970) Geographic size variations in birds and its relationship with climate. Ecology, 51, 365$375 \quad 390$.

376 Jetz, W. \& Pyron, R.A. (2018) The interplay of past diversification and evolutionary isolation with present 377 imperilment across the amphibian tree of life. Nature Ecology \& Evolution, In Press.

378 Kelly, R.M., Friedman, R. \& Santana, S.E. (2018) Primary productivity explains size variation across the $379 \quad$ Pallid bat's western geographic range. Functional Ecology, 32, 1520-1530.

380 Lindsey, C.C. (1966) Body sizes of poikilotherm vertebrates at different latitudes. Evolution, 20, 456-465.

381 McNab, B.K. (2010) Geographic and temporal correlations of mammalian size reconsidered: a resource rule. $382 \quad$ Oecologia, 164, 13-23.

383 Measey, G.J. \& Van Dongen, S. (2006) Bergmann's rule and the terrestrial caecilian Schistometopum 384 thomense (Amphibia: Gymnophiona: Caeciliidae). Evolutionary Ecology Research, 8, 1049-1059. 385 Meiri, S. (2011) Bergmann's rule: what's in a name? Global Ecology and Biogeography, 20, 203-207. 386 Meiri, S., Bauer, A.M., Chirio, L., Colli, G.R., Das, I., Doan, T.M., Feldman, A., Castro-Herrera, F., 387 Novosolov, M., Pafilis, P., Pincheira-Donoso, D., Powney, G., Torres-Carvajal, O., Uetz, P. \& Van Damme, R. (2013) Are lizards feeling the heat? A tale of ecology and evolution under two temperatures. Global Ecology \& Biogeography, 22, 834-845.

Meiri, S., Brown, J.H. \& Sibly, R.M. (2012) The ecology of lizard reproductive output. Global Ecology and Biogeography, 21, 592-602.

Meiri, S. \& Dayan, T. (2003) On the validity of Bergmann's rule. Journal of Biogeography, 30, 331-351.

Meiri, S., Dayan, T. \& Simberloff, D. (2005) Biogeographical patterns in the Western Palearctic: the fastingendurance hypothesis and the status of Murphy's Rule. Journal of Biogeography, 32, 369-375.

Moreno-Azocar, D.L., Perotti, M.G., Bonino, M.F., Schulte, J.A., Abdala, C.S. \& Cruz, F.B. (2015) Variation in 396 body size and degree of melanism withina lizards clade: is it driven by latitudinal andclimatic gradients?

Nevo, E. (1973) Adaptive variation in size of cricket frogs. Ecology, 54, 1271-1278.

Olalla-Tarraga, M.A. (2011) "Nullius in Bergmann" or the pluralistic approach to ecogeographical rules: a reply to Watt et al. (2010). Oikos, 120, 1441-1444.

Olalla-Tarraga, M.A. \& Rodriguez, M.A. (2007) Energy and interspecificbody size patterns of amphibian faunas in Europe and North America:anurans follow Bergmann's rule, urodeles its converse. Global Ecology and Biogeography, 16, 606-617. 
404 Olalla-Tarraga, M.A., Rodriguez, M.A. \& Hawkins, B.A. (2006) Broad-scale patterns of body size in 405 squamate reptiles of Europe and North America. Journal of Biogeography, 33, 781-793.

406 Olalla-Tarraga, M.A., Diniz-Filho, J.A., Bastos, R.P. \& Rodriguez, M.A. (2009) Geographic body size 407 gradients in tropical regions: water deficit and anuran body size in the Brazilian Cerrado. Ecography, $408 \quad 32,581-590$.

409 Olson, V.A., Davies, R.G., Orme, C.D.L., Thomas, G.H., Meiri, S., Blackburn, T.M., Gaston, K.J., Owens, 410 I.P.F. \& Bennett, P.M. (2009) Global biogeography and ecology of body size in birds. Ecology Letters, $411 \quad 12,249-259$.

412 Oufiero, C.E., Adolph, S.C., Gartner, G.E.A. \& Garland, T. (2011) Latitudinal and climatic variation in body 413 size and dorsal scale counts in Sceloporus lizards: a phylogenetic perspective. Evolution, 65, 3590$414 \quad 3607$.

415 Pagel, M. (1999) Inferring the historical patterns of biological evolution. Nature, 401, 877-884.

416 Paradis, E., Claude, J. \& Strimmer, K. (2004) APE: analyses of phylogenetics and evolution in R language. 417 Bioinformatics, 20, 289-290.

418 Peters, R.H. (1983) The ecological implications of body size, Cambridge University Press, Cambridge.

419 Pincheira-Donoso, D. (2010) The balance between predictions and evidence and the search for universal 420 macroecological patterns: taking Bergmann's rule back to its endothermic origin. Theory in $421 \quad$ Biosciences, 129, 247-253.

422 Pincheira-Donoso, D., Hodgson, D.J. \& Tregenza, T. (2008) The evolution of body size under environmental 423 gradients in ectotherms: why should Bergmann's rule apply to lizards? BMC Evolutionary Biology, 8 , $424 \quad 68$.

425 Pincheira-Donoso, D. \& Hunt, J. (2017) Fecundity selection theory: concepts and evidence. Biological $426 \quad$ Reviews, 92, 341-356.

427 Pincheira-Donoso, D. \& Meiri, S. (2013) An intercontinental analysis of climate-driven body size clines in 428 reptiles: no support for patterns, no signals of processes. Evolutionary Biology, 40, 562-578.

429 Pincheira-Donoso, D., Tregenza, T. \& Hodgson, D.J. (2007) Body size evolution in South American 430 Liolaemus lizards of the boulengeri clade: a contrasting reassessment. Journal of Evolutionary Biology, $431 \quad 20,2067-2071$.

432 Pinheiro, J., Bates, D., DebRoy, S. \& Sarkar, D. (2018) nlme: Linear and Nonlinear Mixed Effects Models. $R$ $433 \quad$ package version $3,1-137$.

434 Pough, F.H., Andrews, R.M., Crump, M.L., Savitzky, A.H., Wells, K.D. \& Brandley, M.C. (2015) Herpetology, $435 \quad$ Oxford University Press, Oxford. 
de Queiroz, A. \& Ashton, K.G. (2004) The phylogeny of a species-level tendency: species heritability and possible deep origins of Bergmann's rule in tetrapods. Evolution, 58, 1674-1684.

R Development Core Team (2017) R: A language and environment for statistical computing, R Foundation for Statistical Computing, Vienna.

Richards, S.A. (2005) Testing ecological theory using the information-theoretic approach: examples and cautionary results. Ecology, 86, 2805-2814.

Riemer, K., Guralnick, R.P. \& White, E.P. (2018) No general relationship between mass and temperature in endothermic species. eLife, 7, e27166.

Roff, D.A. (2002) Life history evolution, Sinauer Associates, Sunderland.

Rosenzweig, M.L. (1968) The strategy of body size in mammalian carnivores. American Midland Naturalist, 80, 299-315.

Scharf, I., Feldman, A., Novosolov, M., Pincheira-Donoso, D., Das, I., Böhm, M., Uetz, P., Torres-Carvajal, O., Bauer, A., Roll, U. \& Meiri, S. (2015) Late bloomers and baby boomers: ecological drivers of longevity in squamates and the tuatara. Global Ecology \& Biogeography, 24, 396-405.

Schluter, D. \& Pennell, M.W. (2017) Speciation gradients and the distribution of biodiversity. Nature, 546, $48-55$.

Sibly, R.M. \& Brown, J.H. (2007) Effects of body size and lifestyle on evolution of mammal life histories. Proceedings of the National Academy of Sciences of the United States of America, 104, 17707-17712.

Slavenko, A., Feldman, A., Allison, A., Bauer, A.M., Böhm, M., Chirio, L., Colli, G.R., Das, I., Doan, T.M., LeBreton, M., Martins, M., Meirte, D., Nagy, Z.T., Nogueira, C., Pauwels, O.S.G., Pincheira-Donoso, D., Roll, U., Wagner, P., Wang, Y. \& Meiri, S. (2019) Global patterns of body size evolution in squamate reptiles are not driven by climate. Global Ecology \& Biogeography, 28, 471-483.

Smith, F.A. \& Lyons, S.K. (2013) Animal body size. Linking pattern and process across space, time, and taxonomic group, University of Chicago Press, Chicago and London.

Stearns, S.C. (1992) The evolution of life histories, Oxford University Press, Oxford.

Steele, W.K. \& Louw, G.N. (1988) Caecilians exhibit cutaneous respiration and high evaporative water loss. South African Journal of Zoology, 23, 134-135.

Vitt, L.J. \& Caldwell, J.P. (2014) Herpetology. An introductory biology of amphibians and reptiles, Academic Press, Massachusetts.

Wells, K.D. (2007) The ecology and behavior of Amphibians, Chicago University Press, Chicago.

Yom-Tov, Y. \& Geffen, E. (2006) Geographic variation in body size: the effects of ambient temperature and precipitation. Oecologia, 148, 213-218. 
468 Yom-Tov, Y. \& Nix, H. (1986) Climatological correlates for body size of five species of Australian mammals.

469 Biological Journal of the Linnean Society, 29, 245-262.

470

471

472

473

474

475 
Table 1: Results of multiple and univariate phylogenetic regressions (under the PGLS part of the table), and multi-model inference of caecilian body size against environmental predictors. Phylogenetic regressions all revealed significant phylogenetic signal, with Pagel's lambda ranging between $0.55-0.83$ in all models. Significant relationships are in boldface. Geographic (i.e., latitude as predictor) and environmental analyses performed separately.

\begin{tabular}{|c|c|c|c|c|c|c|c|c|}
\hline \multirow[b]{2}{*}{ Predictors } & \multicolumn{4}{|c|}{ PGLS } & \multicolumn{2}{|r|}{ Univariate Models } & \multicolumn{2}{|r|}{ Multivariate Models } \\
\hline & $\lambda$ & $R^{2}$ & $F(\mathrm{df})$ & $P$ & Slope & 95\% Cl (Lower, Upper) & Slope & 95\% Cl (Lower, Upper) \\
\hline \multicolumn{9}{|l|}{ Global Models } \\
\hline Latitude & 0.581 & 0.002 & $0.28(1,181)$ & 0.60 & 0.037 & $(-0.054,0.128)$ & - & - \\
\hline Multivariate Model (Environ)a & 0.579 & 0.05 & $1.72(5,177)$ & 0.13 & - & - & - & - \\
\hline Mean Precipitation & 0.594 & 0.03 & $5.29(1,181)$ & 0.02 & -0.064 & $(-0.120,-0.009)$ & -0.061 & $(-0.122,-0.000)$ \\
\hline Precipitation Seasonality & 0.563 & 0.003 & $0.51(1,181)$ & 0.48 & -0.021 & $(-0.080,0.037)$ & -0.043 & $(-0.108,0.022)$ \\
\hline Mean Temperature & 0.568 & 0.01 & $1.20(1,181)$ & 0.27 & -0.029 & $(-0.082,0.023)$ & -0.015 & $(-0.071,0.041)$ \\
\hline Temperature Seasonality & 0.581 & 0.01 & $1.36(1,181)$ & 0.25 & 0.034 & $(-0.024,0.092)$ & 0.030 & $(-0.042,0.102)$ \\
\hline Net Primary Productivity & 0.605 & 0.02 & $2.91(1,181)$ & 0.09 & -0.051 & $(-0.111,0.008)$ & -0.038 & $(-0.105,0.029)$ \\
\hline \multicolumn{9}{|l|}{ America Models } \\
\hline Latitude & 0.593 & 0.001 & $0.07(1,88)$ & 0.79 & 0.01 & $(-0.069,0.091)$ & - & - \\
\hline Multivariate Model (Environ)a & 0.615 & 0.11 & $2.09(5,84)$ & 0.08 & - & - & - & - \\
\hline Mean Precipitation & 0.622 & 0.03 & $2.33(1,88)$ & 0.13 & -0.17 & $(-0.386,0.047)$ & -0.20 & $(-0.469,0.059)$ \\
\hline Precipitation Seasonality & 0.576 & 0.03 & $2.53(1,88)$ & 0.12 & -0.15 & $(-0.336,0.039)$ & -0.19 & $(-0.399,0.012)$ \\
\hline Mean Temperature & 0.584 & 0.01 & $0.5(1,88)$ & 0.48 & -0.17 & $(-0.648,0.313)$ & -0.05 & $(-0.577,0.478)$ \\
\hline Temperature Seasonality & 0.600 & 0.01 & $0.81(1,88)$ & 0.37 & 0.21 & $(-0.244,0.659)$ & 0.12 & $(-0.376,0.621)$ \\
\hline Net Primary Productivity & 0.590 & 0.04 & $3.95(1,88)$ & 0.05 & -0.48 & $(-0.959,0.001)$ & -0.46 & $(-0.966,0.035)$ \\
\hline \multicolumn{9}{|l|}{ Fossorial Species Models } \\
\hline Latitude & 0.581 & 0.003 & $0.54(1,170)$ & 0.47 & 0.02 & $(-0.034,0.075)$ & - & - \\
\hline Multivariate Model (Environ)a & 0.561 & 0.06 & $2.07(5,166)$ & 0.07 & - & - & - & - \\
\hline Mean Precipitation & 0.590 & 0.04 & $6.52(1,170)$ & 0.01 & -0.19 & $(-0.329,-0.043)$ & -0.18 & $(-0.328,-0.031)$ \\
\hline Precipitation Seasonality & 0.561 & 0.003 & $0.44(1,170)$ & 0.51 & -0.04 & $(-0.154,0.079)$ & -0.08 & $(-0.209,0.059)$ \\
\hline Mean Temperature & 0.561 & 0.01 & $1.54(1,170)$ & 0.22 & -0.22 & $(-0.567,0.132)$ & -0.15 & $(-0.527,0.226)$ \\
\hline Temperature Seasonality & 0.579 & 0.01 & $1.94(1,170)$ & 0.17 & 0.15 & $(-0.060,0.353)$ & 0.12 & $(-0.125,0.372)$ \\
\hline Net Primary Productivity & 0.603 & 0.02 & $3.04(1,170)$ & 0.08 & -0.24 & $(-0.515,0.029)$ & -0.20 & $(-0.501,0.098)$ \\
\hline
\end{tabular}


Aquatic Species Models

Latitude

Mean Precipitation

Precipitation Seasonality

Mean Temperature

Temperature Seasonality

Net Primary Productivity

$\begin{array}{llll}\mathbf{0 . 7 0 9} & 0.04 & 0.41(1,9) & 0.54 \\ \mathbf{1 . 0 0 0} & 0.82 & 4.62(5,5) & 0.06 \\ \mathbf{0 . 4 8 8 ^ { \star }} & 0.11 & 1.11(1,9) & 0.32 \\ \mathbf{1 . 0 0 0} & 0.31 & 4.12(1,9) & 0.07 \\ \mathbf{0 . 6 7 1} & 0.01 & 0.07(1,9) & 0.79 \\ \mathbf{0 . 5 1 9} & 0.25 & 3.06(1,9) & 0.11 \\ \mathbf{0 . 8 8 9} & 0.10 & 1.01(1,9) & 0.34\end{array}$

$\begin{array}{ll}-0.03 & (-0.151,0.086) \\ - & - \\ 0.14 & (-0.263,0.538) \\ -0.05 & (-0.250,0.151) \\ 0.10 & (-1.125,1.332) \\ -0.52 & (-1.262,0.213) \\ -0.34 & (-0.796,0.116)\end{array}$

-

$0.12 \quad(-0.329,0.560)$

$-0.05 \quad(-0.250,0.151)$

$0.10 \quad(-1.125,1.332)$

$-0.42 \quad(-0.911,0.070)$

$-0.34 \quad(-0.784,0.113)$

aThis multivariate model combines all five environmental predictors, and excludes latitude. 
483 Figure 1. Global distribution of caecilians. The maps show (A) the distribution of caecilian species-richness 484 (the colour gradient shows variation in the number of coexisting species in the same area, as per the values 485 shown in the vertical bar), and (B) the geographic distribution of median body sizes per grid cell (colour 486 gradients along the horizontal bar displays variation in caecilian body sizes on the map).

487
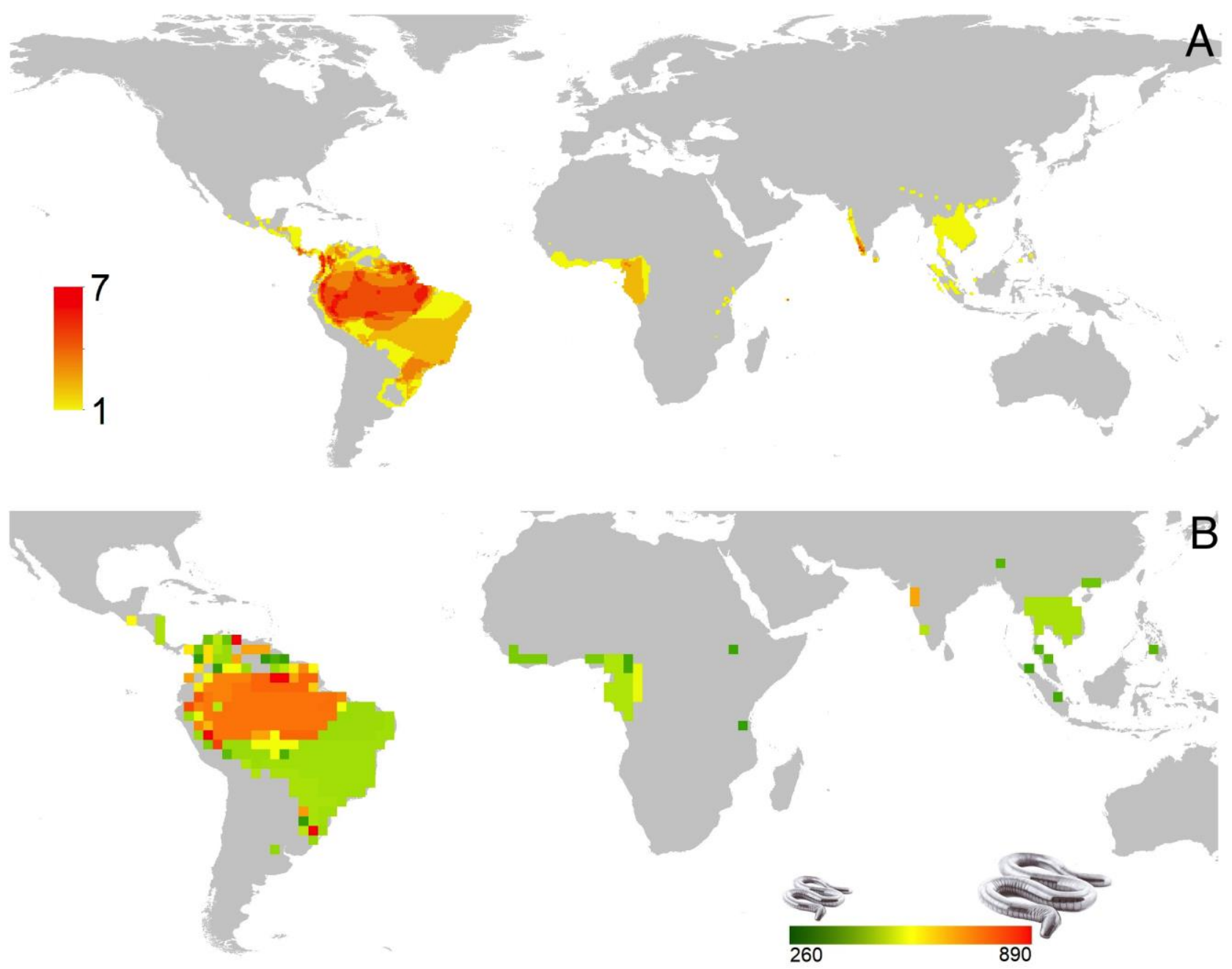
496 Figure 2. Frequency distribution of caecilian body sizes. Distributions expressed as raw body length (A) and 497 as log-transformed body length (B).

498

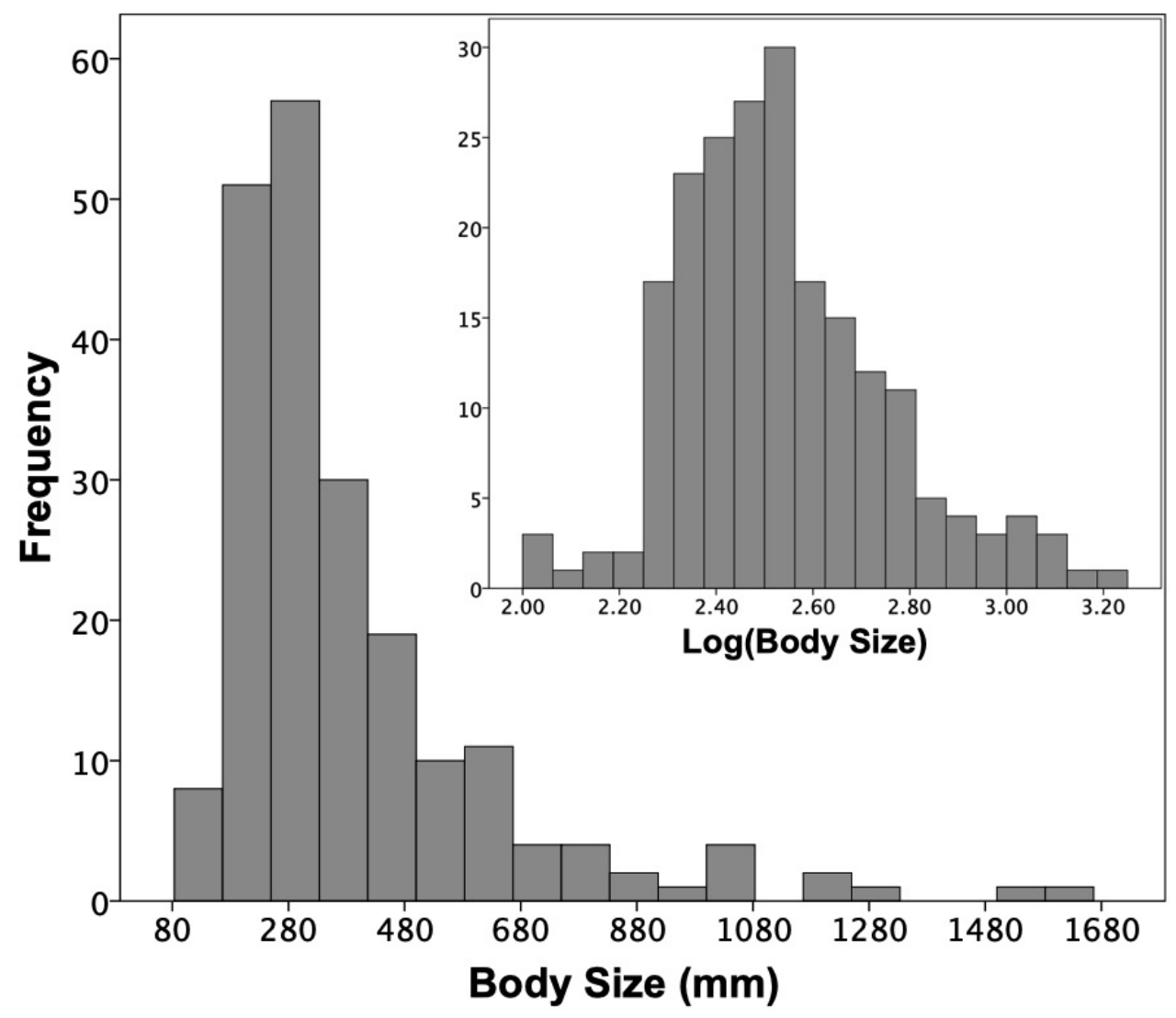

499

500

501

502

503

504

505

506

507

508

509

510

511

512

513 
514 Figure 3. Slopes of phylogenetic regression of log-transformed caecilian body size against log-transformed

515 environmental predictors scaled to zero mean and unit standard deviation in all three analyses, points

516 represent AIC-weighted average slope parameters, and whiskers are $95 \%$ confidence intervals. When

517 confidence intervals span zero, the slopes are considered non-significant. Black points and confidence

518 whiskers represent model-averaged slopes from a full multiple regression of body size against environmental 519 parameters. Red points and confidence whiskers represent the slopes of univariate regressions of body size 520 against each environmental predictor.

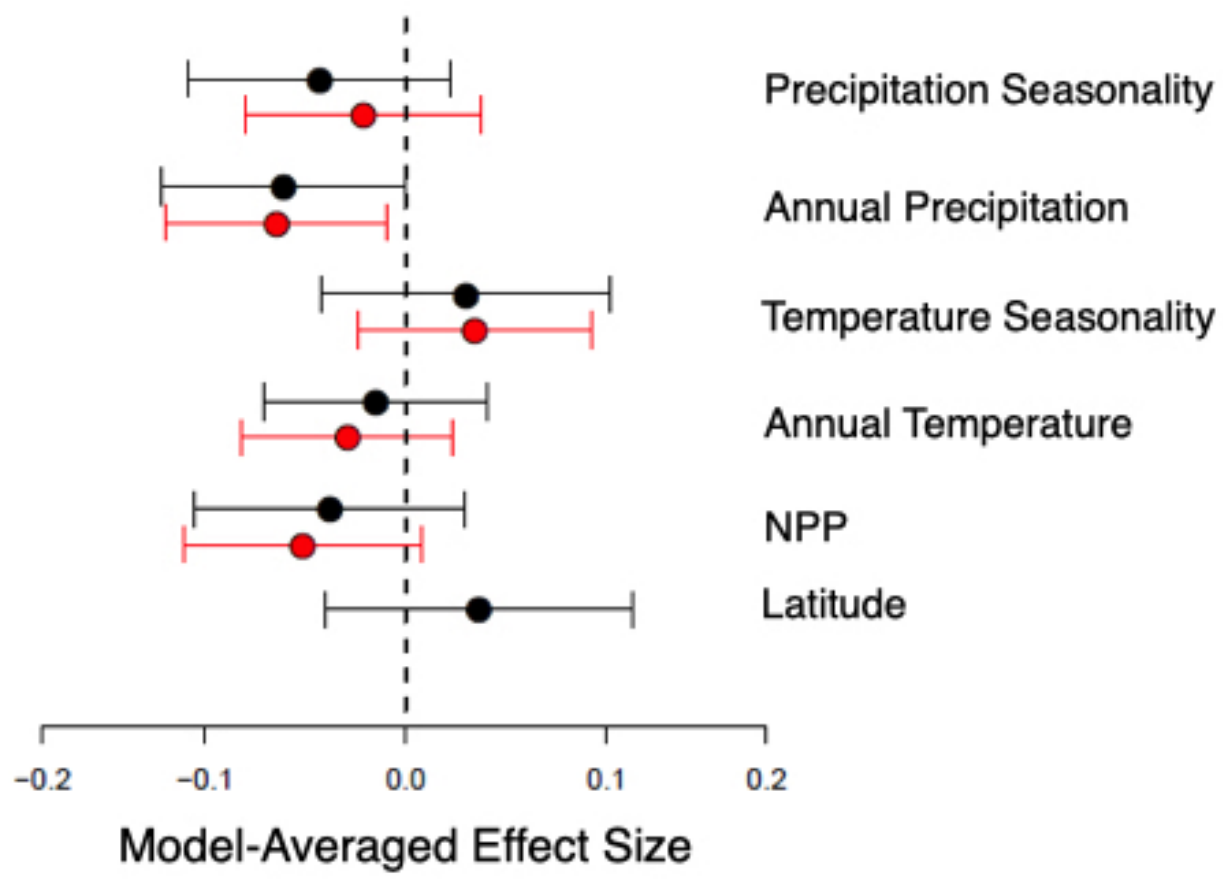

521 